\title{
Reduction in drug related suicide in Scotland 1990-1996: an artefactual explanation
}

\author{
T Squires, D Gorman, J Arrundale, S Platt, P Fineron
}

Forensic Medicine

Unit, Department of Pathology, University of Edinburgh, Teviot Place, Edinburgh EH8 9AG

T Squires

P Fineron

Lothian Health, Edinburgh

D Gorman

General Register Office for Scotland, Edinburgh

J Arrundale

Research Unit in Health and

Behavioural Change,

University of

Edinburgh, Edinburgh

S Platt

Correspondence to:

Dr T Squires.

Accepted for publication 3 March 1999
Deaths in Scotland are coded according to the International Classification of Diseases (Revision 9) (ICD9) by the Registrar General for Scotland (GRO) and published annually. This paper highlights the effect on the drug related suicide rate (deaths coded as ICD9 E950) caused by drug overdose deaths coded to ICD 9 304, "drug dependence".

\section{Method}

Data were extracted from the Annual Reports of the Registrar General for Scotland between 1990 and 1996.

The three digit ICD9 codes relevant to drug related deaths are E950 ("Suicide and self inflicted poisoning by solid or liquid substances"), E980 ("Poisoning by solid or liquid substances, undetermined whether accidentally or purposely inflicted"), 304 ("Drug dependence"), and 305 ("Nondependent abuse of drugs": the majority of these deaths involve alcohol but the category is included for completeness). The drug related accident codes (primarily E850-859, "Accidental poisoning by drugs, medicaments and biologicals"), while not accounting for many deaths, are also included (fig 1).

\section{Results}

Table 1 illustrates changes in the frequency and composition of drug related deaths during the period 1990-96. Whereas there was a gradual but modest rise (from 152 in 1990 to 185 in 1996) in drug related suicides and no clear

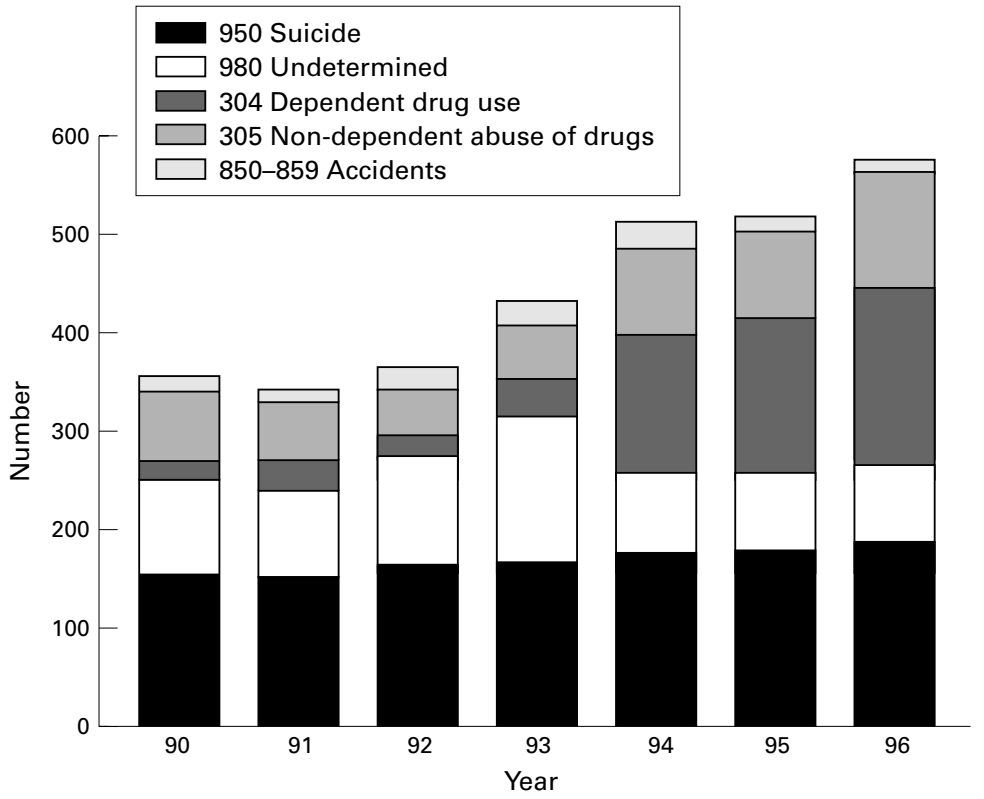

trend in accidental drug related deaths over the same period, there was a marked increase in "drug dependence" deaths (304) (from a mean of 26.0 during 1990-93 to a mean of 159.3 in 1994-96) and a sharp decline in "undetermined" drug related deaths (E980) (from a mean of 113.3 to a mean of 81.0) The combined total of suicide (E950) and undetermined drug related deaths (E980) fell from a mean of 271 in 1990-93 to 257 in 1994. For drug dependence (304) and undetermined deaths (E980) in particular the change in frequency of use between 1993 and 1994 is very marked. Overall, there is a significant difference in the coding of drug related deaths between 1990-93 and 1994-96 ( $\chi^{2}=86.70$, df $=4, \mathrm{p}<0.001)$.

\section{Discussion}

When there is an apparent discontinuity in health (including mortality) statistics over a relatively short timescale, the most likely explanation is artefactual (administrative) rather than substantive. Although the GRO did not change policy or introduce new guidelines concerning the coding of drug related deaths during the period under review, we argue that the sudden increase in the use of "drug dependence" (304) in 1994 largely resulted from the implementation of a new channel of information between medicolegal investigators and the GRO. Since 1994, and complementary to the information provided by the Procurators Fiscal (legal officials responsible for the investigation of sudden death in Scotland), pathologists in Scotland complete form ME4 in all cases in which death involved "drugs, solvents or poisons". ${ }^{2}$

In addition to identifying more drug related deaths, this procedure provides the GRO with new information about the nature of the drug(s) misused and whether the deceased was drug dependent. The pathologist can mention all drugs identified at postmortem toxicology and also drugs noted by the police from the history of the person, including those that were not regarded as being contributory to the cause of death. This method of supplying information to the coding authority directly from the medical investigator is uniquely Scottish. In this context, the primary benefit is that the pathologist's medical opinion is communicated to the coder directly in a form that is not limited by the form of the death certificate nor mediated through the legal authorities.

It is generally the case that for coding purposes the external causes of death (the " $E$ " codes) take precedence over the clinical causes. An otherwise prima facie 304 drug related 
Table 1 Drug related deaths in Scotland 1990-1996 by ICD 9 code (\% of total drug deaths)

\begin{tabular}{|c|c|c|c|c|c|c|}
\hline & \multicolumn{6}{|c|}{ International classification of diseases (ICD9) code } \\
\hline & $\begin{array}{l}304(\%) \text { drug } \\
\text { dependent }\end{array}$ & $\begin{array}{l}305(\%) \text { non-dependent } \\
\text { abuse of drugs }\end{array}$ & $\begin{array}{l}950(\%) \text { drug related } \\
\text { suicide }\end{array}$ & $\begin{array}{l}980(\%) \text { drug related } \\
\text { "undetermined" }\end{array}$ & $\begin{array}{l}850-859(\%) \\
\text { accident }\end{array}$ & Total \\
\hline 1990 & $17(4.8)$ & $71(19.9)$ & $152(42.7)$ & $99(27.8)$ & $17(4.8)$ & 356 \\
\hline 1991 & $30(8.7)$ & $58(16.9)$ & $151(44.0)$ & $90(26.2)$ & $14(4.1)$ & 343 \\
\hline 1992 & $20(5.5)$ & $47(12.9)$ & $162(44.5)$ & $114(31.3)$ & 21 & 364 \\
\hline 1993 & $37(8.6)$ & $53(12.3)$ & $166(38.4)$ & $150(34.7)$ & $26(6.0)$ & 432 \\
\hline 1994 & $140(27.4)$ & $86(16.8)$ & $175(34.2)$ & $82(16.0)$ & $28(5.5)$ & 511 \\
\hline 1995 & $158(30.6)$ & $86(16.6)$ & $177(34.2)$ & $80(15.5)$ & $16(3.1)$ & 517 \\
\hline 1996 & $180(31.3)$ & $117(20.3)$ & $185(32.2)$ & $79(13.7)$ & $14(2.4)$ & 575 \\
\hline
\end{tabular}

death that exhibits the standard of proof (in Scotland, on the balance of probabilities) sufficient to establish suicidal intent is, therefore, coded to E950. However, because "drug dependence" (304) is a more precise description of the cause of death it takes precedence over "undetermined" (E980) if there is evidence of dependent drug use. It is precisely this evidence of dependent drug use that is now communicated to the GRO by the forensic pathologist (after his or her assessment of the police, necropsy and toxicology reports). Hence, many deaths that are now considered to fall within 304 would have been coded to E980 ("undetermined") before the use of form ME4. This almost certainly accounts for the change in the relative frequency of 304 and E980 deaths over the period. To our knowledge this effect has not been reported in other medicolegal jurisdictions.

The potential consequence of this change for our monitoring of suicide trends is profound. The combined suicide (ICD9 E950-959) and undetermined (ICD9 E980-989) rate is generally considered to be the most accurate indicator of the "true" incidence of self inflicted death in the community. ${ }^{3}$ Given that many deaths previously coded to E980 now seem to be coded to 304 , it is probable that the decrease in the combined drug related suicide rate observed after 1993 is at least partly artefactual resulting from more precise coding of death based on improved information. We suggest that this is valid even if, as is probable, there are other non-artefactual factors, especially rapidly changing patterns in drug use, which also account for changes over the period of the study. While it is, therefore, difficult to quantify the extent of the artefactual reduction in suicides, it is clear that comparisons between pre- and post-1994 figures would be particularly unreliable. This is important information for those who track progress against targets for the reduction of suicide (for example, health departments and health authorities) and those who evaluate the effects of drug use in society.

1 Arrundale J, Cole SK. Collection of information on drug-related deaths by the General Register Office for Scotland. Edinburgh: Register General for Scotland, 1995.

2 The Scottish Office Home and Health Department. 1994 Health in Scotland, Edinburgh: HMSO, 1995.

3 Charlton J, Kelly S, Dunnell K, et al. Trends in suicide deaths in England and Wales. Population Trends 1992;69: 10-16. 